\section{Taking Our Hands Off the Wheel}

$I^{\prime}$

t happened first in the airline industry: automated navigation was adopted as standard practice in airplanes years ago. When you consider all forms of travel, we are probably safest in the air. Now the automobile industry is moving in that direction. Although we can't drive "hands-free" quite yet, new cars have safety features now standard that were formerly optional. I drive a new sedan that, among many features, has a wheel that quivers if I get too close to the edge of the lane, will park itself if I ask it to, sounds an alarm if I try to change lanes with a car in my blind spot, and refuses to lock if I've left the key inside. I love this added level of safety.

Meanwhile, cancer medicine is way behind. Template treatment regimens with built-in stops for safety, such as hepatitis or pregnancy testing, only became commonplace when electronic medical records (EMRs) came on board. But even that could be improved with requirements for other safety measures, such as testing for dihydropyrimidine dehydrogenase deficiency or UTG1A1 mutations. This is where clinical pathways are needed. And I am completely in favor of this.

Ample examples of the implementation of clinical pathways resulting in better outcomes are available. Dana Farber implemented pathways in stage IV lung cancer, and survival improved post implementation. ${ }^{1}$ Of course, advances in treatment may have contributed to improved outcomes as well. A retrospective analysis of patients with colon cancer treated according to level 1 pathways also showed improved survival and a lower rate of chemotherapy-related admissions. ${ }^{2}$ Regarding cost, when efficacy is similar, such as with cetuximab and panitumumab, giving the less expensive option in the pathway can save a lot of money. ${ }^{3}$

Guidelines, such as those from NCCN, take us only so far. [Editor's note: NCCN licenses NCCN content for use with technology systems like EMRs and pathways.] It is still left up to the clinician to make the final decision about an intervention. But because we often don't have time to look up every detail in a guideline, we may only explore this when we aren't sure. With treatment options changing so rapidly and new drugs approved right and left, it's easy to be a bit behind and out of date.

I maintain that every EMR should allow us to enter patient-specific details, such as disease stage, comorbidities, and even molecular profiling. The EMR should then give us the best regimen to use based on efficacy, safety, and cost. And the recommendation should be hyperlinked to source data, such as the registration trial for the drug in that indication, in case the information is new for us and we need to review.

If you are worried that our positions could be assumed by robots, think again. We will always need to be the final arbiter in making decisions, because neither guidelines nor pathways can "think" of everything. In time, we will get smarter and incorporate more and more data into these algorithms, especially with regard to safety and tolerance of therapy in older patients. Bringing value to safe and effective therapy should be everyone's goal. Clinical pathways are a start.

\section{References}

1. Jackman DM, Zhang Y, Dalby $C$, et al. Cost and survival analysis before and after implementation of DanaFarber clinical pathways for patients with stage IV non-small-cell lung cancer. J Oncol Pract 2017;13:346-352.

2. Hoverman JR, Cartwright TH, Patt DA, et al. Pathways, outcomes, and costs in colon cancer: retrospective evaluations in two distinct databases. J Oncol Pract 2011;7(3 Suppl):52s-59s.

3. Ellis PG, $\mathrm{O}^{\prime} \mathrm{Neil} B \mathrm{BH}$, Earle MF, et al. Clinical pathways; management of quality and cost in oncology networks in the metastatic colorectal cancer setting. J Oncol Pract 2017:13:e522-529.

WHAT DO YOU THINK? To submit a Letter to the Editor, email JNCCN@nccn.org or log into www.editorialmanager.com/JNCCN.

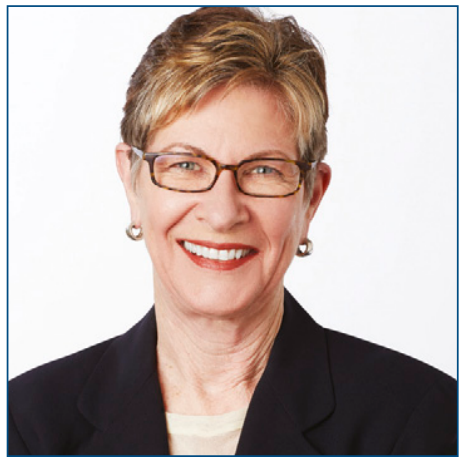

MARGARET TEMPERO, MD

Margaret Tempero, MD, is a Professor of Medicine and Director of the UCSF Pancreas Center and editor-in-chief of JNCCN. Her research career has focused on pancreatic ductal adenocarcinoma, especially in the area of investigational therapeutics. Dr. Tempero has served on the ASCO Board of Directors and as ASCO President. She currently serves on the ASCO Conquer Cancer Foundation Board. She codirected the AACR/ASCO Methods in Clinical Cancer Research and taught this course and similar courses in Europe and Australia. She was founding Chair of the $\mathrm{NCl}$ Clinical Oncology Study Section and served as a member and Chair of the $\mathrm{NCl}$ Board of Scientific Counselors Subcommittee A. She is a member of the Scientific Steering Committee and Chair of the Clinical and Translational Study Section for the Cancer Prevention \& Research Institute of Texas. She is or has been on the Scientific Advisory Boards of the Lustgarten Foundation, the Pancreatic Cancer Action Network, the V Foundation, The Alberta Canada Cancer Board, and the EORTC. She served as a member of the Oncology Drug Advisory Committee for the FDA. She has served as Deputy Director and Interim Director for the UNMC Eppley Cancer Center. She is Chief Emeritus of the Division of Medical Oncology at UCSF. She served as the founding Deputy Director and was later Director of Research Programs at the UCSF Helen Diller Family Comprehensive Cancer Center.

doi: $10.6004 /$ jnccn.2020.0013

The ideas and viewpoints expressed in this editorial are those of the author and do not necessarily represent any policy, position, or program of NCCN. 